(125)

\title{
Efficacy of Leaf Extracts of Invasive Tithonia diversifolia Against Selected Fungal Pathogens Causing Leaf Spot Diseases
}

\author{
Mapa M.H.M.N.*, Damunupola J.W. and Jayasundera A.C.A. \\ University of Peradeniya, Sri Lanka \\ *nisansala.mapal@gmail.com
}

\begin{abstract}
Invasive alien plant species are recognized as a significant threat for species extinction globally. Sri Lanka, been a tropical country has the optimum conditions for distribution of various invasive plant species, and they are a threat to the local biodiversity. Many research have been carried out towards utilization of such plants as a method of successful eradication. Horticultural growers use synthetic fungicides to overcome the problems caused by plant pathogenic fungi, and it has lead to many negative impacts on environment and human health. Consequently, demand for the natural fungicides is increasing. With this background, there is a potential to use invasive plants as natural fungicides due to the presence of bioactive compounds within them. Tithonia diversifolia is an invasive plant species in Sri Lanka. The aim of this study was to find the efficacy of $T$. diversifolia leaf extracts to inhibit selected fungal pathogens causing leaf spots in ornamental plants. Extractions were done using methanol, dichloromethane and n-hexane. Antifungal activity was tested using standard methods against Curvularia sp., Fusarium sp., and Alternaria sp. Highest inhibition for Curvularia sp. and Fusarium sp. were obtained in n-hexane and methanolic leaf extracts respectively. Minimum inhibitory concentration (MIC) for the Curvularia sp. in n-hexane was $0.0175 \mathrm{~g} / \mathrm{ml}$ and MIC for Fusarium sp. in methanolic extract was less than $0.0175 \mathrm{~g} / \mathrm{ml}$. Leaf anatomical observations revealed three types of trichomes. They were non-grandular and two types of glandular trichomes; capitate and non-capitate. Preliminary tests and Gas chromatographic analysis were done to determine the phytochemical constituents of the three extracts. Results revealed that the three extracts are different from each other where methanolic and dichloromethane were capable in extracting more secondary metabolic compounds. Methanolic and dichloromethane were tested for total phenolics and methanolic extract had the highest content with a 4.4963 $\mu \mathrm{g} / \mathrm{ml}$. Therefore, it can be concluded that leaf extracts from $T$. diversifolia have the potential to be used as a natural fungicide on disease causing fungi in plants while conserving biodiversity.
\end{abstract}

Keywords: Invasive species, Tithonia diversifolia, Natural fungicides, Phytochemical, Biodiversity 